\title{
As palavras na ponta-da-língua e o funcionamento integrado das funções psicológicas superiores
}

\author{
Marcus Vinicius Borges Oliveira \\ Universidade Federal da Bahia (UFBA), Salvador, Bahia, Brasil \\ marcus.oliveira.fono@gmail.com
}

DOI: http://dx.doi.org/10.21165/el.v45i2.629

\begin{abstract}
Resumo
Conhecido na literatura da área como "tip-of-the-tongue", esse fenômeno refere-se ao momento em que o sujeito procura uma palavra, acompanhado da sensação de que essa já vai surgir ou de que já lhe escapou. Por meio de uma perspectiva histórico-cultural, influenciada por autores como Luria, Vygotsky, dentre outros, refletimos sobre as palavras na ponta-da-língua como um acontecimento que depende do funcionamento integrado das diversas funções psicológicas superiores, discutindo brevemente o papel da percepção e da atenção nesse processo, dando ênfase maior na relação entre a linguagem e a memória. A partir da análise qualitativa de dados provenientes de situações em que as palavras ficaram na ponta-da-língua, daremos visibilidade a essa dificuldade tanto na normalidade quanto nas afasias.
\end{abstract}

Palavras-chave: palavras na ponta-da-língua; neurolinguística; pesquisa qualitativa; afasia; perspectiva histórico-cultural.

\section{Tip-of-the-Tongue Words and Integrated Functioning of Higher Psychological Functions}

\begin{abstract}
Known in the field of Neurolinguistics as "tip-of-the-tongue", this phenomenon refers to the state when someone searches for a word, accompanied by the feeling that it will soon come or that it has already escaped from them. Through a historical-cultural approach, influenced by authors such as Luria, Vygotsky, among others, this paper reflects on tip-of-the-tongue words as an event that depends on the integrated functioning of higher psychological functions. It also discusses the role of perception and attention, placing greater emphasis on the relationship between language and memory. Through the qualitative analysis of data from tip-of-the-tongue situations, it is given this difficulty visibility in both normality and aphasia.
\end{abstract}

Keywords: tip-of-the-tongue phenomenon; neurolinguistics; qualitative research; aphasia; historical-cultural approach.

\section{Introdução}

Conhecido na literatura da área como tip-of-the-tongue, doravante referido como TOT, este fenômeno tem intrigado pesquisadores de diferentes áreas por mais de um século $^{1}$. A ocorrência do TOT refere-se ao momento em que o sujeito procura uma

\footnotetext{
${ }^{1}$ Este artigo não tem como objetivo revisar a literatura sobre o tema, até porque já existem livros atuais como os de Schwartz (2002), de Brown (2012) e de Schwartz e Brown (2014) - que cobrem responsavelmente a literatura tradicional e se configuram como referências obrigatórias aos que desejarem se aprofundar no assunto.
} 
palavra, acompanhado da sensação de que essa já vai surgir ou de que já lhe escapou. Trata-se, portanto, não apenas de um momento de inacessibilidade, mas também da sensação que o acompanha - saber que se sabe a palavra buscada, mas com a impossibilidade de evocá-la no momento da enunciação, ainda que se possa sentir uma forte sensação de presença da palavra ausente.

Dependendo do grau de formalidade da situação, bem como da relevância da palavra que falta - se é, por exemplo, uma palavra-chave num discurso técnico ou científico ou se surge num diálogo cotidiano informal - o falante recorre a diferentes estratégias discursivas: pode admitir publicamente que não se lembra dela, solicitando ajuda aos seus interlocutores, ou produzir paráfrases e circunlóquios que, muitas vezes, lhe dão o tempo necessário para se "lembrar" ou para ser lembrado pelos outros. Muitas vezes, entretanto, a palavra simplesmente não vem. Devido à rapidez da produção de enunciados na interação verbal, podem surgir no lugar dela outras palavras que a ela se relacionam, seja por traços sonoros, situacionais, conceituais ou afetivos, como defende Luria (2001).

Este artigo trata especificamente das palavras na ponta-da-língua em relação ao funcionamento integrado das funções psicológicas complexas ${ }^{2}$. Neste sentido, discutiremos brevemente o papel tanto da percepção e da atenção, porém, daremos ênfase no relacionamento entre memória (e esquecimento) e linguagem dentro de uma perspectiva histórico-cultural, dando grande relevância ao estudo do signo. Para tanto, inicialmente, se faz necessário entender, na perspectiva histórico-cultural, fortemente baseada nos conceitos postulados por Luria e Vygotsky, como as funções psicológicas superiores estão integradas, constituindo o funcionamento do cérebro como um sistema funcional complexo. Ao longo do artigo, alguns dados serão trazidos porque entendemos que revelam a natureza dessas interações entre as funções superiores, tanto no que diz respeito à normalidade quanto às afasias.

\section{As funções psicológicas superiores sob uma perspectiva histórico-cultural}

A perspectiva histórico-cultural, como já dissemos, orienta as reflexões que desenvolvemos neste trabalho e é influenciada por autores como Luria, Vygotsky, Bakhtin e Ponzio, dentre outros. Com relação ao funcionamento cerebral e ao desenvolvimento das funções psicológicas superiores, nos respaldamos nas teorias formuladas por Luria e Vygotsky, como já dissemos.

Luria considerava Vygotsky um grande aliado, que compartilhava dos mesmos interesses, que identificava a crise pela qual a psicologia se encontrava na época e que era o principal teórico marxista reconhecido:

Não é exagero dizer que Vygotsky era um gênio. Em mais de cinco décadas de trabalho em meio científico, nunca mais encontrei qualquer pessoa cujas qualidades se aproximassem das de Vygotsky: sua clareza mental, sua habilidade na identificação da estrutura essencial de problemas complexos, a extensão de seu conhecimento em diversos campos, e a capacidade que tinha de antever o desenvolvimento futuro de sua ciência (LURIA, 1992, p. 3).

\footnotetext{
2 Este artigo é parte das reflexões que compõe a tese intitulada "As Palavras na Ponta-da-língua: Uma Abordagem Neurolinguística" (OLIVEIRA, 2015).
} 
Influenciado pelas teorias de Vygotsky, Luria (1973) aprofunda a noção de que as funções psicológicas superiores são sociais em sua origem, complexas e hierarquicamente organizadas nas suas estruturas. Para Kotit-Friedgut (2006), Luria expõe um método dialético de estudo das funções psicológicas, em que a natureza influencia o desenvolvimento humano, ao mesmo tempo em que também se modifica pela ação do homem. Essa interação dialética cria novas condições de existência.

Contrapondo-se tanto à visão mecanicista da localização cerebral, interessada em mapear as áreas cerebrais e suas funções, quanto à visão holística do cérebro - que o concebia como uma massa indiferenciada - Luria, em consonância com os postulados de Vygotsky (2005, 2007), desenvolve o conceito de Sistema Funcional Complexo ${ }^{3}$.

O cérebro, segundo Luria, pode ser dividido em três unidades estruturais e funcionais. As três unidades são as divisões funcionais mais delimitadas, cada uma subdividida em diferentes zonas. Essas estruturas correspondem a sistemas funcionais, dinâmicos e historicamente mutáveis, sem uma localização anatômica fixa (LURIA, $1973)^{4}$.

A unidade I é reguladora dos chamados "estados de consciência" e suas estruturas estão situadas no tronco cerebral. Essa unidade desempenha importante papel na regulação do estado cortical e no nível de vigilância. Já as unidades II e III são corticais e desempenham diferentes funções. A unidade II - que engloba os lobos temporal, parietal e occipital - seria responsável por receber, analisar e armazenar informações. Os sistemas desta unidade possuem especificidade modal; suas partes componentes estão adaptadas para recepção de informações visuais, auditivas, vestibulares ou sensoriais gerais. A unidade II (assim como a III) é formada por zonas primárias, secundárias e terciárias. A zona primária seria responsável pela recepção das informações sensoriais, enquanto que a zona secundária sintetizaria essas informações para o trabalho da zona terciária - a mais complexa de todas, justamente por ser responsável pela integração das informações de diferentes analisadores. Assim, dados visuais, táteis-cinestésicos ou auditivos são analisados individualmente até a chegada à zona terciária. É justamente nessa área que as informações serão associadas e integradas. De acordo com Luria (1981, p. 55), essas zonas desempenham papel essencial na "memorização de experiência organizada ou, em outras palavras, não apenas na recepção e codificação de informações, mas no seu armazenamento". São estruturas especificamente humanas, desenvolvidas ao longo da filogênese.

Já a unidade III - constituída pelo lobo frontal - seria responsável pelo controle e avaliação da ação. As especificidades descritas anteriormente, com relação às zonas primárias, secundárias e terciárias, também fazem parte da unidade III, mas neste caso fazendo o caminho inverso ao anteriormente descrito. A zona terciária é igualmente intermodal, enquanto que a zona secundária seria a programadora estrutural e sequencial da ação, que ocorre sob o comando da zona primária. As áreas pré-frontais do cérebro, essenciais para a regulação do estado da atividade, de acordo com Luria (1981),

\footnotetext{
${ }^{3}$ Segundo Noguchi (1997), o conceito de Sistema Funcional Complexo foi introduzido por Anokh in, em 1935, e desenvolvido posteriormente por Luria.

${ }^{4}$ Podemos ver um exemplo disto no estudo de Noguchi $(1997$, p. 40) que busca estudar as relações entre a percepção visual e a memória. De acordo com a autora, uma alteração semântica não repercute nos processos mentais superiores de forma exclusivamente linguística ou exclusivamente visual ou mnêsica. "[...] Só é possível entender essas alterações na relação entre estes processos".
} 
consistem nas últimas partes dos hemisférios cerebrais a serem formadas, ocupando neles cerca de um quarto da massa total. São muito pouco desenvolvidas nos demais animais, sendo um pouco maiores nos primatas.

É de fundamental importância essa visão integrativa intermodal, assumida por esse modelo, principalmente em relação às funções complexas superiores. Citamos um trecho em que Luria $(1981$, p. 60) sintetiza bem a importância dessa unidade:

O homem não somente reage passivamente a informações que chegam a ele, como também cria intenções, formas plenas e programas para as suas ações, inspeciona a sua realização e regula seu comportamento de modo a que ele se conforme a esses planos e programas; finalmente, o homem verifica a sua atividade consciente, comparando efeitos de suas ações com as intenções originais e corrigindo erros que ele tenha cometido.

Como já dissemos na introdução deste texto, nosso objetivo é o de relacionar aspectos linguístico-cognitivos para compreender o processo subjacente ao TOT. Antes de aprofundarmos a reflexão sobre a relação entre linguagem e memória, julgamos necessário tratar, ainda que brevemente, de questões acerca da percepção e da atenção, uma vez que estão funcionalmente imbricadas.

A percepção, como entendida por Luria, tem caráter ativo. Não somente sentimos, mas percebemos que sentimos, em um complexo processo de codificação do material percebido que se realiza somente com a estreita ligação com a linguagem. Para Luria, a percepção "nunca acontece sem a participação direta da linguagem" (1981, p. 200). Para entendermos melhor esse processo, vejamos como o autor a descreve:

O processo de percepção é, assim, evidentemente, de natureza complexa. Ele começa pela análise da estrutura recebida, ao ser recebida pelo cérebro, em um grande número de componentes ou pistas que são, subsequentemente codificados ou sintetizados e inseridos nos sistemas móveis correspondentes. Este processo de seleção e síntese de aspectos correspondentes é de natureza ativa e ocorre sob a influência direta das tarefas com que o individuo se defronta. Realiza-se com o auxílio de códigos já prontos (especialmente códigos de linguagem) que servem para colocar o aspecto percebido no seu devido sistema e para conferir a ele um aspecto de caráter geral ou categórico (LURIA, 1981, p. 200).

Dessa forma, a percepção incorpora sempre um estado de comparação com uma hipótese original. No caso dos TOTs, por exemplo, em cada momento singular, se reiteram características que se baseiam em experiências prévias, tanto do ponto de vista da cultura, quanto do ponto de vista da sua internalização para o próprio sujeito. Para Luria, decorre dessa experiência prévia que, em alguns casos, a percepção se torne familiar, fazendo com que esse processo seja retomado por meio de "atalhos". Isso poderia explicar por que a sensação de um TOT pode ocorrer mesmo para uma palavra que não existe, o que na literatura é conhecido como "TOT ilusório 5 ".

\footnotetext{
${ }^{5}$ Este tipo de TOT pode ser visto com mais profundidade no trabalho de Schwartz (2002), no qual o autor elicia um TOT com perguntas que não possuem resposta. Um exemplo do procedimento seria perguntar “Qual o nome da capital de Brasília?". Ainda que não exista uma capital de Brasília, esta pergunta pode eliciar estados de TOT.
} 
Da mesma forma que a percepção, para Luria (1981), também a atenção é um processo ativo. Devido a seu desenvolvimento durante a filogênese, se evidencia nas formas superiores, humanas, de atenção voluntária. Essa função psicológica superior também depende de um funcionamento integrado, desde o estágio de vigilia, forma elementar de atenção regulada por mecanismos em que participa o tronco cerebral superior, até o reconhecimento seletivo de determinado estímulo, que inclui a inibição de outros semelhantes.

Para finalizar esta seção, vejamos um relato retrospectivo ${ }^{6}$ de um TOT que dá visibilidade à integração das funções psicológicas superiores. A narrativa retroativa é também um momento de reflexão sobre o fenômeno e, por isso, um momento em que prevalece a atividade metalinguística, com aumento da atenção voluntária:

Dado I: O sujeito EA, sexo feminino, estava no meio de uma tarefa quando sente um cheiro e fica com a palavra na ponta-da-língua.

(01) Ontem, estava correndo um pouco, com "mil coisas para fazer" e havia pessoas me esperando. Neste momento, entrei na cozinha de casa, para pegar um copo d'água e senti um cheiro de... Perguntei para minha amiga que já estava lá: "Este cheiro é de....". (não me lembrei da palavra, ficando com a sensação de palavra na ponta-da-língua) "erva doce?" Eu mesma respondi: "Não. É...." Nisso fiz um gesto levantando a mão direita para a direita, em "arco", que me remeteu a um tufo, e a palavra saiu: "Erva cidreira".

Como entender que uma sensação de natureza olfativa tenha desencadeado um TOT e, por sua vez, a realização de um gesto tenha contribuído para o surgimento da palavra? Do ponto de vista neurofisiológico, vimos que a memória depende do trabalho integrado das áreas associativas do Bloco II, que sintetiza informações auditivas, táteis, visuais, gustativas e também aspectos ligados ao movimento e mesmo à melodia cinética da ação. Por outro lado, a própria relação de um signo com outros (verbais ou não-verbais) participa ativamente do processo de busca da palavra e de sua solução. Isso sem falar nos enlaces afetivos, como é propriamente colocado por Luria (2001).

O sujeito estava em meio a uma atividade cotidiana quando a sensação da falta da palavra e o desejo de encontrá-la interrompem a própria atividade e lhe tomam a consciência. De modo geral, não existe como escapar de um TOT. Podemos, no máximo, ignorá-lo. No dado acima, o sujeito é impelido à solução, mesmo que tenha que deixar de lado as "mil coisas" para fazer e as "pessoas esperando". Continua a tentar encontrar a palavra perguntando à amiga, que também não soube dizê-la. De certa forma, já intuía que se tratava de uma erva, visto que o nome que surge durante a busca é erva doce, que ela imediatamente nega. No relato do blog, o sujeito EA ainda informa que "erva cidreira" é o seu chá favorito, o que explica a sua motivação em encontrar a palavra, que somente vem quando o TOT desencadeia um gesto - que representa um

\footnotetext{
${ }^{6}$ De acordo com Oliveira (2015), um dos procedimentos eficientes para analisar os TOTs são os relatos retrospectivos de momentos em que as palavras estavam na ponta-da-língua. Esse relato foi retirado do blog chamado "As palavras na ponta-da-língua", onde hospedamos um link para acesso ao protocolo de pesquisa e abordamos assuntos relacionados às palavras na ponta-da-língua, com suporte de charges, vídeos, textos e entrevistas. Este instrumento de pesquis a foi divulgado em eventos científico-acadêmicos, visando não só compartilhar informações e achados sobre o tema da pesquisa, mas também para obter colaborações - relatos de ocorrências de TOTs. Uma descrição mais detalhada desses aspectos metodológicos pode ser vista em Oliveira (2015).
} 
arco e remete ao tufo de erva cidreira - gesto icônico por natureza, conforme veremos mais adiante. O sujeito diz que "a palavra saiu". Não temos como saber qual a natureza dessa lembrança, mas parece que o sujeito confere à palavra, nesse contexto, uma certa autonomia.

As lembranças despertadas pelo cheiro também são amplamente descritas em trabalhos de caráter não-cientiffico e nas obras literárias. É interessante assinalar que já existem testes preparados com odores específicos, o que já se configurou como um tipo de estímulo eficaz para eliciar os TOTs ${ }^{7}$.

\section{O estudo da relação entre memória e linguagem dentro de uma perspectiva histórico cultural}

Como colocado anteriormente, a linguagem não pode ser resumida às regras estruturais da língua, ao seu sistema, da mesma forma que a memória não pode ser reduzida aos seus processos neuroquímicos e à sua contraparte biológica. Tanto a linguagem como a memória são sistemas complexos, de natureza semiótica, que emergem ao longo do desenvolvimento humano (OLIVEIRA; NOVAES-PINTO, $2014)^{8}$.

Vygotsky e Luria (1996) buscam explicar como a memória se desenvolve ao longo da história do homem. Para os autores, a memória do homem primitivo seria extremamente acurada, podendo ser considerada por nós como extraordinária: Segundo os autores (1996, p. 113), "[...] a memória biológica (orgânica), ou a chamada unidade mnemônica, cuja base está impregnada na plasticidade de nosso sistema nervoso (em sua capacidade de armazenar traços de estímulos exteriores e de reproduzi-los) atinge seu desenvolvimento máximo no homem primitivo".

Porém, essa extraordinária capacidade humana é meramente o exercício cotidiano da memória, na ausência (ou carência) de mecanismos lógicos e abstratos, visto que, filogeneticamente, havia um estágio cognitivo primário, indiferenciado, eidético, essencialmente ligado à necessidade de reproduzir um objeto tal qual previamente apresentado. A memória, nesse estágio, funcionaria como força elementar. Podemos dizer que ela dominaria o homem, dado seu descontrole. O seu desenvolvimento histórico, de acordo com os autores (1996, p. 14), começa a partir do momento em que o homem passa a dominá-la, pelo uso de instrumentos:

A partir da capacidade de encontrar caminhos, isto é, da capacidade de utilizar pistas como signos que the revelam e lembram figuras complexas inteiras - a partir do uso de um signo - o homem primitivo, em determinado estágio de seu desenvolvimento, chega pela primeira vez à criação de um signo artificial.

Gradualmente, devido ao uso de instrumentos auxiliares, a memória (enquanto função cognitiva) se modifica, qualitativamente, e se distancia da percepção direta,

\footnotetext{
${ }^{7}$ Recomendamos, para aqueles que estiverem especialmente interessados no tema, a leitura do capítulo Odor Knowledge, Odor Naming, and the "Tip-of-the-Nose" Experience, de Fredrik U. Jönsson and Richard J. Stevenson, no livro organizado por Schwartz e Brown (2014).

${ }^{8}$ Isto pode ser visto em outros trabalhos da Neurolinguística de orientação enunciativo discursiva, tais como Beilke (2009); Novaes-Pinto (2012) e Oliveira e Novaes Pinto (2014), dentre outros.
} 
ganhando capacidade de abstração. Um exemplo disso é o nó que utilizamos para lembrar de algo, explicitado na passagem abaixo, de Vygotsky (2007, p. 50):

Quando uma pessoa ata um nó no lenço para ajudá-la a lembrar de algo, ela está, essencialmente, construindo o processo de memorização, fazendo com que um objeto externo relembre-a de algo; ela transforma o processo de lembrança numa atividade externa. Esse fato, por si só, é suficiente para demonstrar a característica fundamental das formas superiores de comportamento. $\mathrm{Na}$ forma elementar, alguma coisa é lembrada; na forma superior os seres humanos lembram alguma coisa. No primeiro caso, graças a ocorrência simultânea de dois estímulos que afetam o organismo, um elo temporário é formado; no segundo caso, os seres humanos, por si mesmos, criam um elo temporário através de uma combinação artificial de estímulos.

Sobre o papel que as atividades externas têm com relação à organização das funções psicológicas superiores, Vygotsky postulou o princípio de organização extracortical, posteriormente desenvolvido por Luria. Esse conceito é fundamental para entender $\mathrm{o}$ impacto cultural dos instrumentos historicamente esculpidos (signos, objetos) no desenvolvimento das funções complexas superiores. Aparentemente simples, esses instrumentos modificam qualitativamente a estrutura psicológica da memória, estendendo-a para além das dimensões biológicas do sistema nervoso humano, permitindo a incorporação de signos. Isto se dá pelo fato de o homem ter aprendido a criar ligações - de caráter mediado - entre o signo e seu significado, e representa uma transição da chamada memória natural para uma memória cultural. Um exemplo dessa capacidade humana de desenvolver instrumentos para "dominar sua memória" é o quipú.

De acordo com Luria e Vygotsky (1996, p. 117), os quipús - que significam cordões com nós, na língua peruana - "são recursos auxiliares de memória convencionais muito difundidos por povos primitivos que exigiam conhecimento preciso por parte daquele que amarrava esses nós". Esses nós tinham diferentes funções como marcadores mnemônicos que permitiam a codificação e a decodificação de mensagens.

De maneira análoga, na ontogênese, os autores dirão que a transição de formas naturais para formas culturais, ou seja, o abandono da função natural da memória, que constitui o desenvolvimento da memória da criança para a do adulto, faz valer um sistema de associações. A principal diferença é que "o homem primitivo inventou ele mesmo seus sistemas de memorização, enquanto a criança apropria-se, o mais das vezes, de sistemas já prontos que ajudam a lembrar" (LURIA; VYGOTSKY, 1996, p. 186).

A partir do momento em que a fala passa a dominar o comportamento da criança, a função da memória muda acentuadamente e qualitativamente. Aqui vale citar a máxima de Vygotsky (2007, p. 49), que diz que "para as crianças, pensar significa lembrar, no entanto, para o adolescente, lembrar significa pensar". Se em sua forma natural, a memória de alguma coisa é lembrada graças à coocorrência de estímulos outrora registrados em um elo temporário, em seu caráter mediado (ou indireto, também na terminologia de Vygotsky, 2007), os homens aprenderam a criar este elo necessário. Daí Vygotsky e Luria (1996, p. 213) reafirmarem que a essência da memória é lembrar ativamente por meio de signos: 
Tem sido constatado com bastante precisão que, na idade escolar, a memória pictográfica evolui para a memória verbal. Se, na idade pré-escolar, a memória dos objetos não era mais fraca, mas até mais forte do que a memória de palavras, agora o quadro se altera radicalmente e a criança em idade escolar geralmente começa a adquirir uma memória de natureza verbal. As palavras e as formas lógicas começam a desempenhar o papel de ferramentas decisivas para a rememoração. Por essa época, vai desaparecendo o tipo de miraculosa memória pictográfica, conhecida pelo termo eidetismo.

A criança só conseguiria, na fase anterior ao processo anteriormente descrito, associar uma figura a uma palavra, se estabelecesse com esta palavra um elo associativo, o que depende da natureza do signo e dos seus elos prévios. O autor dá um exemplo do pesquisador que mostra a figura de um machado e pede que a criança lembre da palavra "sol". A criança apontou uma pequena mancha amarelada no desenho e conseguiu facilmente resolver a questão, pois a associou com o sol. O movimento, nesse caso, vai da representação direta para a simbolização mediada. As crianças, nesse estágio intermediário, estão entre o processo elementar e o completamente instrumental. Para o autor, na medida em que a criança cresce, o que muda não é tanto a estrutura de uma função (memória) isolada, mas também as relações interfuncionais envolvidas no processo de lembrança, principalmente com a linguagem e o pensamento.

No caso dos adultos, a memória já tem esses processos internalizados. De acordo com Vygotsky e Luria (1996), já possuímos um vasto material, constituído de marcas de experiências prévias, que reunimos e utilizamos ativamente a cada rememoração. Para lembrarmos de algo, associamos o que é novo à nossa experiência anterior; criamos ativamente uma estrutura que recebe os novos elementos.

Para os interesses deste artigo, é necessário aprofundar a questão eminentemente sígnica. De acordo com Vygotsky (2007, p. 34), as atividades semióticas modificam o esquema simples e direto do comportamento elementar, que corresponde a uma via de "mão única", de causa e efeito. Por outro lado, o autor afirma que a operação com signos requer um elo intermediário entre o estímulo e a resposta, que seria um estímulo de segunda ordem, colocado no interior da operação, modificando-a. Se antes havia um único direcionamento entre estímulo $(\mathrm{S})$ e resposta $(\mathrm{R})$, agora temos um ato complexo, mediado, que faz com que o sujeito esteja ativamente engajado.

Vygotsky observa que o signo também age de modo reverso, sobre o indivíduo. Acompanhando o desenvolvimento qualitativo da memória na criança, o autor sugere que, em um estágio pré-escolar, não é comum que o signo auxiliar leve a criança para uma ação reversa, mas que a leve para outro signo, evocando uma nova cadeia associativa. Porém, essa operação progride para um estágio mais avançado onde a reversibilidade é confiável. Essa reversibilidade é que possibilita que o sujeito crie uma associação (como um nó), que no futuro o faz retomar a associação prévia.

Ao situar o TOT como um evento ligado à emergência de um campo semântico, Luria está, ao mesmo tempo, referindo-se tanto à natureza mnemotécnica da associação, quanto à interferência de uma palavra na seleção de uma outra palavra, involuntariamente. Vejamos na citação abaixo, de Luria (2001), questões essenciais para a reflexão que se segue:

Sendo assim, a recordação de palavras e a denominação dos objetos são um processo de escolha da palavra procurada dentre uma rede de associações que surgem 
involuntariamente; por isso, as dificuldades na recordação de palavras, bem conhecidas em psicologia, tratam-se menos de insuficiências da memória do que de resultados do excesso de palavras e conceitos que emergem involuntariamente e que dificultam substancialmente $\mathrm{o}$ ato da escolha.

Com isto, relacionam-se às observações dos psicólogos norte-americanos R. Brown e D. McNeill publicadas no artigo intitulado "Tip of the tongue Phenomenon". O sujeito procura recordar uma denominação e acredita perceber que esta já vai aparecer, que se encontra na "ponta-da-língua", mas na realidade surgem palavras diferentes, ligadas a procurada seja por traços sonoros, morfológicos, situacionais ou conceituais (LURIA, 2001, p. 89)

Como explicar que Luria se refira à dificuldade de recordação e à não insuficiência de memória? Justamente por não entender a memória apenas em seu aspecto mnemônico, acreditamos que a referência à "recordação" se dá justamente pela impossibilidade de desatar os nós constituídos pela associação da memória com a linguagem. Este é o insight que Luria dá para o entendimento do fenômeno dos TOTs.

Não podemos deixar de dizer que esses processos serão, posteriormente, na história da humanidade, interiorizados de tal forma que permitirão, por meio de uma arte apurada, fazer com que indivíduos construam seus palácios mentais e ali aloquem suas memórias de maneira impressionante, como é narrado no livro "A arte da memória", de Yates (2007), referida, atualmente, como "mnemotécnica", um termo que não dá a dimensão dessa arte na antiguidade.

\section{A análise de um dado de um sujeito afásico; o processo em câmera lenta}

A dificuldade de encontrar palavras, de forma tão peculiar, é verificada tanto na normalidade quanto em algumas patologias que impactam o funcionamento da linguagem, como as afasias. Neste contexto, a procura pela palavra pode revelar angústia e sofrimento, ao contrário do que ocorre na fala dos não afásicos, que imediatamente reorganizam sua fala para lidar com a falta da palavra, nas afasias há um impacto importante, fazendo com que os enunciados, muitas vezes, se tornem mais disfluentes, muito marcados por hesitações (pausas, repetições etc.), entrecortados por falas cristalizadas, como: "eu não consigo falar", "eu sei, mas não...", ou acompanhados por gestos que indicam que a palavra está na ponta-da-língua (apontando a língua).

A relação dos TOTs com a afasia é contemplada na literatura da área, geralmente relacionada ao tema do acesso lexical. Ao revisitar os principais artigos da área, Oliveira (2015) constatou a carência de estudos que se aproximem dos fenômenos qualitativamente. Neste artigo, defendemos o referencial histórico cultural como uma forma de estudar qualitativamente a dificuldade de encontrar as palavras. A escolha desse aparato qualitativo se dá pela conjuntura de trabalhos ligados a Neurolinguística de orientação enunciativo-discursiva, área que vem se desenvolvendo desde os trabalhos de Coudry (2001), na década de 80. De acordo com Novaes-Pinto (2012, p. 118), "ao contrário de postular modelos abstratos, valendo-se de resultados obtidos em baterias de testes-padrão, tão caros à neurociência, a Neurolinguística de orientação enunciativodiscursiva busca compreender o funcionamento linguístico cognitivo de enunciados dialógicos [...]. 
Segundo Coudry (2001), a afasia exibe o funcionamento da linguagem em "câmera lenta", o que a torna um campo ainda mais privilegiado para compreender o funcionamento da linguagem.

Dentro da perspectiva histórico cultural, as reflexões de Luria e Vygotsky foram influenciadas pelo pensamento de Roman Jakobson, no campo da Linguística, autor que defende e demonstra a importância da linguística no estudo das afasias. De acordo com Akhutina (2003, p. 130): “The joining together of Vygotsky's, Luria's and Jakobson's ideas was natural and productive. This connection was bilateral and multistaged". Para a autora, as ideias de Vygostky e Jakobson sobre a linguagem têm muito em comum, já que 'both of them share W. von Humboldt's and A. Potebnia's understanding of language as an activity, its creative nature and historic conditioning, its systemic structure, and the interaction of language and thought". A relação de Jakobson com Luria é ainda mais explícita, principalmente no que diz respeito à afasia, em que a experiência clínica de Luria dialoga com os princípios do funcionamento da linguagem proposto por Jakobson.

As reflexões de Jakobson (1981) sobre os dois eixos de funcionamento da linguagem: sintagmático e paradigmático $^{9}$ sem dúvida podem contribuir significativamente para a compreensão dos fenômenos relativos às dificuldades de encontrar palavras. O eixo paradigmático (ou metafórico) está relacionado à seleção das unidades, dentre uma gama de elementos, enquanto que o outro eixo, o sintagmático (ou metonímico), se refere ao contexto de combinação dos elementos previamente selecionados. Esses dois eixos organizam simultaneamente os processos de seleção e combinação na produção da linguagem. São interdependentes, pois para que ocorra a combinação é necessário selecionar e, da mesma forma, toda seleção está subordinada ao contexto da combinação das unidades, que ocorre em todos os níveis linguísticos (JAKOBSON, 1981[1954]). Segundo o autor, nos casos dos indivíduos afásicos, tal relação se caracterizaria pela predominância do funcionamento de um eixo sobre o outro, gerando os distúrbios de similaridade e de contiguidade.

Como uma forma de demonstrar o que foi dito até aqui, analisaremos qualitativamente um recorte de uma sessão videogravada com um afásico ${ }^{10}$, que dá visibilidade ao imbricamento entre a linguagem e a memória, assim como de possíveis efeitos dessa relação em um sujeito afásico.

Dado II: Episódio dialógico ocorrido no $\mathrm{CCA}^{11}$, em uma sessão em que estavam o pesquisador (BO), uma estagiária em Fonoaudiologia e o sujeito afásico (MG). BO

\footnotetext{
${ }^{9}$ Eixos que são referentes às operações propostas por Saussure (2006/1916).

10 Dado o caráter deste artigo, não aprofundaremos nas questões metodológicas ligadas à abordagem microgenética. Para conhecer diferentes formas de aproximação do estudos dos TOTs com a perspectiva his tórico cultural, ver Oliveira (2015).

11 O Centro de Convivência de Afásicos (CCA) foi inaugurado a partir de uma ação conjunta entre os Departamentos de Linguística e de Neurologia da Universidade Estadual de Campinas (UNICAMP). Este centro funciona no IEL (Instituto de Estudos da Linguagem) onde ocorrem atendimentos ao afásicos, baseado na uso efetivo da linguagem. Este centro serve como lócus para diversas pesquisas, principalmente dos pesquisadores e estudantes ligados à Neurolinguística de orientação Enunciativa Discursiva. De acordo com Santana, Novaes Pinto e Oliveira (2015), "O trabalho realizado no CCA, além de promover "efeitos terapêuticos" no funcionamento linguístico-cognitivo dos sujeitos afásicos, tem contribuído sensivelmente para a qualidade de vida desses sujeitos, assim como de s uas famílias". O grupo do CCA de que participei foi o grupo III, formado por fonoaudiólogos, linguistas e outros
} 
mostra a foto de Indiana Jones para que o sujeito diga se lembra do personagem e se consegue nomeá-lo.

\section{Quadro 1. Transcrição de sessão fonoaudiológica}

\begin{tabular}{|c|c|c|c|}
\hline Turno & Sujeitos & Enunciado & Informações contextuais \\
\hline 1 & $\mathrm{BO}$ & Só precisa me dizer o personagem. & \\
\hline 2 & MG & É, então vai ser mais difícil. & \\
\hline 3 & $\mathrm{BO}$ & $\begin{array}{l}\text { Você acha mais difícil do que o nome dele? Aí } \\
\text { você assustou a gente. }\end{array}$ & Todos riem \\
\hline 4 & MG & Não... É o Haris son... É... o Ford. & \\
\hline 5 & $\mathrm{BO}$ & Olha só... Harrison Ford, exatamente. & \\
\hline 6 & MG & $\begin{array}{l}\text { Tá vendo... Eu não posso pensar, se pensar... aí, já } \\
\text { viu! }\end{array}$ & \\
\hline 7 & $\mathrm{BO}$ & $\begin{array}{l}\text { Mas o personagem, vai dizer que o senhor não } \\
\text { lembra? }\end{array}$ & \\
\hline 8 & MG & $\begin{array}{l}\text { É... Eu sei que... ele fez } 4 \text { filmes, de... de um... } \\
\text { histo, histórico, historiador. }\end{array}$ & $\begin{array}{l}\text { MG baixa a cabeça e faz } \\
\text { um esforço para lembrar. }\end{array}$ \\
\hline 9 & $\mathrm{BO}$ & Arqueólogo, não é ? & \\
\hline 10 & MG & $\begin{array}{l}\text { Arqueólogo, que seja... Tesouro não sei das } \\
\text { quantas... etc. }\end{array}$ & $\begin{array}{l}\text { Dá com os ombros, como } \\
\text { se não fosse importante }\end{array}$ \\
\hline 11 & $\mathrm{BO}$ & Que tem aquela musiquinha... & $\begin{array}{l}\text { Neste momento BO } \\
\text { cantarola a famosa música } \\
\text { do filme "Indiana Jones". }\end{array}$ \\
\hline 12 & MG & Exatamente... Índia... Indiana Jones. & $\begin{array}{l}\text { Todos riem quando } \mathrm{MG} \\
\text { acerta o nome. }\end{array}$ \\
\hline 13 & $\mathrm{BO}$ & A musiquinha é batata!!! & \\
\hline
\end{tabular}

$\mathrm{O}$ pesquisador deixa claro, logo de início, que quer que ele diga o nome do personagem. MG se recorda do nome do ator - Harrison Ford. Na sequência, ele tenta se lembrar do nome do personagem da série. MG esclarece que utiliza, segundo seu próprio relato, a estratégia de "ganhar tempo" até encontrar a palavra, falando sobre o assunto. Quando ele diz, no turno 6, "se eu pensar... aí já viu", nos revela que se parar para pensar na palavra, aí é que ela não vem.

Vai dando pistas enquanto se lembra: de que há 4 filmes, nos quais o personagem é um historiador (turno 8) e fala de "tesouro não sei das quantas", tema bastante recorrente nos filmes que ele protagoniza. São indícios de que a palavra esperada, apesar de não vir, está "no entorno" daquelas que surgem. Apesar de dar pistas de que se lembra do filme e do personagem, o nome esperado não vem. Nesse mesmo turno, MG baixa a cabeça e faz um esforço para se lembrar. O nome do personagem só aparece quando o pesquisador resolve cantarolar o famoso trecho da música que acompanha os momentos mais empolgantes do personagem. Vem aos poucos; primeiramente como "india", que rapidamente se transforma em "Indiana Jones". O processo de aparecimento da palavra parece semelhante ao momento anterior, quando ele diz "histo... histórico... historiador". É como se, a partir das pistas sonoras que ele ouve (de si mesmo), conseguisse "resgatar" a palavra toda.

profissionais. Neste grupo, participei das sessões coletivas semanais, também atuando terapeuticamente com alguns dos sujeitos afásicos, desde 2011. 
É muito relevante enfatizar, num processo dialógico como o ocorrido neste episódio, que os conhecimentos partilhados entre pesquisador e pesquisado foram fundamentais para o desfecho que teve. Para Coudry (2001, p. 83), sem "um conjunto de pressuposições indispensáveis ao diálogo" não é possível avaliar coerentemente o afásico, nem interagir com ele buscando soluções para suas dificuldades. É uma "instância dúplice"; o relacionamento intersubjetivo cria condições para a interação, não como um limite de acontecimentos discursivos, mas um lugar onde eles podem ocorrer. Os episódios discursivos, por sua vez, vão ampliando as condições de interação que tornam mais intensa a intersubjetividade.

Dizemos isto porque a avaliação do processo de emergência do TOT, assim como a busca de sua superação, quando não explicitamente colocado ou confirmado pelo sujeito, dependerá da sensibilidade do pesquisador para perceber que o sujeito sabe a palavra, mas que ela não vem. Tal "sensibilidade", por sua vez, decorre de sua experiência não só com o objeto da pesquisa, mas também com a condição de afasia.

MG é um sujeito diferenciado com relação ao que sabe de sua afasia e desenvolveu estratégias eficazes para dizer o que quer, como a de "andar em volta da palavra", ganhando tempo e trazendo à tona outras, a ela relacionadas. MG é discreto com relação à angústia causada pela falta da palavra. Os afásicos, cada qual ao seu modo, aprendem a conviver com isso e, no caso de MG, ele entende que se ficar nervoso ou parar para pensar, vai dificultar a solução. Outro trecho de diálogo com MG pode ajudar a explicitar suas dificuldades, mas também suas soluções, conforme veremos adiante:

Dado III: Inicio de sessão terapêutica com o fonoaudiólogo (BO) e MG, respondendo a pergunta "gostaria que você me dissesse como você se sente quando a palavra fica na ponta-da-lingua". 
Quadro 2. Transcrição de sessão fonoaudiológica

\begin{tabular}{|c|c|c|c|}
\hline Turno & Sujeitos & Enunciado & Informações contextuais \\
\hline 1 & $\mathrm{BO}$ & $\begin{array}{l}\text { Então... Antes de começar, eu gostaria que } \\
\text { você me dissesse como você se sente quando } \\
\text { isso acontece, quando a palavra fica na } \\
\text { ponta-da-língua. }\end{array}$ & \\
\hline 2 & MG & Então, pergunta o que você quer saber. & \\
\hline 3 & $\mathrm{BO}$ & $\begin{array}{l}\text { Como você se sente? Se acontece muito, } \\
\text { se acontece pouco... Queria que você } \\
\text { falasse um pouco sobre isso. }\end{array}$ & \\
\hline 4 & MG & $\begin{array}{l}\text { Olha, é... Como eu tenho... às vezes eu } \\
\text { não consigo lembrar; é... como é que eu } \\
\text { vou dizer assim... O som ainda continua } \\
\text { me atrapalhando, porque... vezes eu quero } \\
\text { falar sobre "Pinda... perdão. "Pinda"... }\end{array}$ & $\begin{array}{l}\text { Fica hesitante... Dá uma } \\
\text { deixa para BO completar a } \\
\text { palavra. }\end{array}$ \\
\hline 5 & $\mathrm{BO}$ & Monhangaba. & \\
\hline 6 & MG & $\begin{array}{l}\text { Pindamonhengaba... Por exemplo, é } \\
\text { difícil, extremamente, eu não consigo às } \\
\text { vezes. Aí eu tenho som. Aí, moral da } \\
\text { história, as pessoas falam, falam. Aí não, } \\
\text { escreve! Aí eu escrevo. Aí eu tenho que } \\
\text { ensinar a fazer a tradução... A grande } \\
\text { minha dificuldade está aí.. Às vezes vem } \\
\text { na memória, eu quero falar, e não } \\
\text { consigo. Aí eu tenho que dar volta, } \\
\text { quando eu fico dando volta, ou eu perco } \\
\text { o início, e ou então, simplesmente as } \\
\text { pessoas não têm saco nem paciência. } \\
\text { Moral da história, quem conhece perto } \\
\text { é fácil porque já fala "é isso que estou } \\
\text { falando". Já foi, vamos embora e vai } \\
\text { embora. Minhas filhas pelo menos me } \\
\text { ajudam nessa parte porque elas obrigam a } \\
\text { falar. Até chegar no "é isso que você quer } \\
\text { saber"? Aí me ensina a falar. }\end{array}$ & \\
\hline
\end{tabular}

Conforme podemos ver por esse relato, MG reflete sobre a dificuldade de ficar com a palavra na ponta-da-língua. Acha que é um problema de memória ou de tradução ${ }^{12}$, Conforme vimos neste texto, desatar o nó, uma vez estabelecido, é praticamente impossível. Daí ele dizer que não lembra, ao mesmo tempo em que acredita que seja uma dificuldade de traduzir, própria da linguagem - passar de uma palavra a outra, de um atributo à palavra-chave, aquela que quer dizer.

O que mais nos interessa no dado é o trecho grifado, que explicita o que ocorre no dado anterior. MG diz que tem que "dar voltas" para chegar à palavra, mas se der uma volta muito grande, perde aquilo que já tinha. Enfim, que o processo não é instantâneo e que é preciso ter paciência. Sua conclusão é a de que é melhor falar com quem o conhece de perto, que tem disposição para ajudá-lo. A esse respeito, os TOTs, sobretudo nos casos de afasia, levam a pensar sobre a importância vital da palavra.

12 Tendo as formulações de Jakobson (1981) no texto "Aspectos linguísticos da tradução" como cenário teórico, podemos dizer que a intuição de MG de que se trata de uma dificuldade de tradução de um signo por outro é bastante precisa. Para Jakobson, o significado de um signo não é mais do que sua tradução por outro, dentro da própria língua (tradução intralingual). 
Vivemos em uma sociedade logocêntrica, em que a perda da palavra traz impacto muito relevante na vida. Ao se tornarem afásicos, os sujeitos ficam reduzidos às suas afasias. Ouvimos deles estórias de exclusão, que revelam certa ignorância, por parte da sociedade, tanto acerca das afasias quanto da própria natureza heterogênea da linguagem. Para uma sociedade produtivista como a nossa, esses sujeitos deixam de existir a partir do momento em que perdem suas funções sociais, o que afasta deles amigos e parentes (NOVAES-PINTO, 2009).

\section{Conclusão}

Neste artigo, refletimos sobre os TOTs como acontecimento que depende do funcionamento integrado das diversas funções psicológicas superiores, discutindo brevemente o papel da percepção e da atenção nesse processo, dando ênfase maior à relação entre linguagem e memória, analisando-a, tanto ontogeneticamente, quanto filogeneticamente. Dentro de uma perspectiva histórico-cultural, apresentamos como a evolução dessas funções se dá através das modificações (neuro)funcionais, a partir do momento em que o homem desenvolve os signos para mediar sua relação com o mundo.

Discutimos sobre o ato de dar um nó para nos lembrarmos de algo, mas também sobre a dificuldade em dissociar um determinado nó daquilo que esse nó lembra. Fica claro que não podemos considerar os TOTs simplesmente como um tipo de esquecimento, o que poderia acontecer se fosse tomado apenas como uma falha na memória. Ao contrário, ressaltamos o caráter incompleto dos TOTs, que vigoram, ao mesmo tempo, como lembrança e esquecimento.

Concluímos dizendo que os TOTs, como diz Novaes Pinto, podem ser comparados à "ponta de um iceberg" (OLIVEIRA, 2015). Com isso, queremos dizer que o entendemos como a interface sensível de processos subjacentes muito mais amplos e complexos, que se dão na relação entre diversas funções psicológicas superiores, que pode ser visto tanto na normalidade quanto em estados patológicos que alteram o funcionamento da linguagem, como no caso aqui descrito, nas afasias.

\section{REFERÊNCIAS}

AKHUTINA, T. V. Roman Jakobson and the Development of Russian Neurolinguistics. In: Journal of Russian and East European Psychology, v. 41, n. 3/4, May-June/JulyAugust, 2003. P. 129-158.

BEILKE, H. M. B. Linguagem e Memória na Doença de Alzheimer: contribuições da neurolinguística para a avaliação da linguagem. 2009. 127 f. Dissertação (Mestrado em Linguística) - Instituto de Estudos da Linguagem, Universidade Estadual de Campinas, Campinas.

BROWN, A. S. The tip of the tongue state. Psychology Press: New York, 2012. 229 p.

COUDRY, M. I. Diário de Narciso: afasia e discurso. São Paulo: Martins Fontes, 2001[1998]. 205 p.

JAKOBSON, R. Dois Aspectos da Linguagem e dois tipos de Afasia. In:

Lingüística e Comunicação. São Paulo: Cultrix. 1981[1954]. 162 p. 
KOTIK-FRIEDGUT, B. Development of the Lurian Approach: A cultural Neurolinguistic Perspective. Neuropsychology Review, v. 16, n. 1, p. 43-52, 2006.

LURIA, A. R. Pensamento e Linguagem: As últimas conferências de Luria. São Paulo: Artmed, 2001. $251 \mathrm{p}$. . The working brain. London: Penguin Books, 1973. 398 p. A construção da mente. São Paulo: Ícone, 1992. 234 p. Fundamentos de Neuropsicologia. São Paulo: Ed. da USP, 1981. 346 p.

NOGUCHI, M. S. A linguagem na Doença de Alzheimer: considerações sobre um modelo de funcionamento linguístico-cognitivo. 1997. 102 f. Dissertação (Mestrado em Linguística) - Instituto de Estudos da Linguagem da Universidade Estadual de Campinas, Campinas.

NOVAES-PINTO, R. C. Dificuldades de encontrar palavras e produção de parafasias nas afasias e nas demências: inferências para o estudo da organização e do acesso lexical. Projeto de Pesquisa Individual (CNPq). Instituto de Estudos da Linguagem, UNICAMP, 2009.

A contribuição do estudo discursivo para uma análise crítica das categorias clinicas. 1999. 271 f. Tese (Doutorado em Linguística) - Instituto de Estudos da Linguagem, Universidade Estadual de Campinas, Campinas.

Cérebro, linguagem e funcionamento cognitivo na perspectiva sócio-históricocultural: inferências a partir do estudo das afasias. Letras de Hoje, Porto Alegre, v. 47, n. 1, p. 55-64, jan./mar. 2012.

OLIVEIRA, M. V. B. Palavras na Ponta-da-língua: uma abordagem neurolinguística. 155 f. Tese (Doutorado em Linguística) - Instituto de Estudos da Linguagem, Universidade Estadual de Campinas, Campinas.

OLIVEIRA, M. V. B.; NOVAES-PINTO, R. C. On the Relation between Memory and Language from a Cultural-Historical Perspective in Neurolinguistics. Southern Semiotic Review. Access on: <http://www.southernsemioticreview.net>. 2014.

SANTANA, A. P.; NOVAES-PINTO, R. C.; OLIVEIRA, M. V. B. Plano Terapêutico Fonoaudiológico (PTF) para Terapia em Grupo com Afásicos, In: Planos Terapêuticos Fonoaudiológicos (PTFs), v. 2, p. 155-166, 2015.

SAUSSURE, F. Curso de Linguística Geral. 27. ed. São Paulo: Cultrix, 2006 [1916]. $278 \mathrm{p}$.

SCHWARTZ, B. L. Tip-of-the-tongue states: Phenomenology, mechanism, and lexical retrieval. Ney Jersey: LEA, 2002. 181 p.

SCHWARTZ, B. L.; BROWN, A. S. Tip-of-the-tongue States and Related Phenomena. USA: Cambrige University Press, 2014. 355 p.

VYGOTSKY, L. S. Pensamento e linguagem. São Paulo: Editora Martins Fontes, 2005[1987]. 193 p.

A formação social da mente. São Paulo: Editora Martins Fontes, 2007. 182 p.

VYGOTSKY, L. S. LURIA, A. R. Estudos sobre a história do comportamento: o macaco, o primitivo e a criança. Porto Alegre: Artes Médicas, 1996. 252 p. 
YATES, F. A. A arte da memória. Campinas: Editora da UNICAMP, 2007. 498 p.

Recebido em: 18/09/2015

Aprovado em: 09/04/2016 